\title{
Chronic central neuropeptide $Y$ infusion in normal rats: status of the hypothalamo-pituitary-adrenal axis, and vagal mediation of hyperinsulinaemia
}

\author{
A. Sainsbury ${ }^{1}$, F. Rohner-Jeanrenaud ${ }^{1}$, I. Cusin ${ }^{1}$, K. E.Zakrzewska ${ }^{1}$, P. A. Halban ${ }^{2}$, R. C. Gaillard ${ }^{3}$, B.Jeanrenaud ${ }^{1}$ \\ ${ }^{1}$ Laboratoires de Recherches Métaboliques, Faculty of Medicine, University of Geneva, Geneva, Switzerland \\ ${ }^{2}$ Laboratoires de Recherche Louis Jeantet, University of Geneva Medical Centre, Geneva, Switzerland \\ ${ }^{3}$ Division d'Endocrinologie et du Métabolisme, Department of Internal Medicine, Centre Hospitalier Universitaire Vaudois, \\ Lausanne, Switzerland
}

\begin{abstract}
Summary Neuropeptide $\mathrm{Y}$ in the hypothalamus is a potent physiological stimulator of feeding, and may contribute to the characteristic metabolic defects of obesity when hypothalamic levels remain chronically elevated. Since corticosterone and insulin are important regulators of fuel metabolism, the longitudinal effects of chronic (6 days) intracerebroventricular infusion of neuropeptide $\mathrm{Y}$ in normal rats on the hypothalamo-pituitary-adrenal axis and on insulin secretion were studied. Neuropeptide Y-infused rats were either allowed to eat ad libitum, or were pair-fed with normophagic control rats. Neuropeptide Y increased the basal plasma concentrations of adrenocorticotropic hormone and corticosterone during the first 2 days of its intracerebroventricular infusion and increased cold stress-induced plasma adrenocorticotropic hormone concentrations. After 4-6 days of central neuropeptide $\mathrm{Y}$ infusion, however, basal plasma adrenocorticotropic hormone and corticosterone concentrations were no different from control values (except in ad libitum-fed rats in which corticosteronaemia remained elevated), they were unaffected by the stress of cold exposure, and the hypothalamic
\end{abstract}

content of corticotropin-releasing factor immunoreactivity was significantly decreased. A state of hyperinsulinaemia was present throughout the 6 days of intracerebroventricular neuropeptide $Y$ infusion, being more marked in the ad libitum-fed than in the pair-fed group. The proportions of insulin, proinsulin, and conversion intermediates in plasma and pancreas were unchanged. Hyperinsulinaemia of the pair-fed neuropeptide Y-infused rats was accompanied by muscle insulin resistance and white adipose tissue insulin hyperresponsiveness, as assessed by the in vivo uptake of 2-deoxyglucose. Finally, bilateral subdiaphragmatic vagotomy prevented both the basal and the marked glucose-induced hyperinsulinaemia of animals chronically infused with neuropeptide $Y$, demonstrating that central neuropeptide Y-induced hyperinsulinaemia is mediated by the parasympathetic nervous system. [Diabetologia (1997) 40: 1269-1277]

Keywords Intracerebroventricular, neuropeptide Y, hypothalamo-pituitary adrenal axis, insulin, proinsulin, vagus nerve, glucose utilisation.
Received: 7 May 1997 and in revised form: 24 July 1997

Corresponding author: Dr. A.Sainsbury, Diabetes Research Group, Garvan Institute of Medical Research, 384 Victoria Street, Darlinghurst, Sydney NSW 2010, Australia

Abbreviations: NPY, Neuropeptide Y; i.c. v., intracerebroventricular; HPA, hypothalamo-pituitary-adrenal; ACTH, adrenocorticotropic hormone; CRF, corticotropin-releasing factor; HPLC, high performance liquid chromatography; TFA, trifluoroacetic acid; BSA, bovine serum albumin; PVN, paraventricular nucleus.
Neuropeptide Y (NPY) is a 36 amino acid peptide of the peripheral and central nervous system [1]. Centrally it is found in particularly high concentrations in the hypothalamus [1], where it is involved in the regulation of many neuroendocrine and autonomic functions [2, 3]. NPY is particularly well known for its role as a potent, physiological stimulator of feeding acting within discrete hypothalamic sites [4].

Defects in the activity of NPY-ergic neurones in the hypothalamus may contribute to the development of obesity, at least in rodents [5]. In support of this hypothesis, elevated levels of NPY and/or its 
transcript have been observed in the hypothalami of genetically obese rodents such as $f a / f a$ and $c p / c p$ rats $[6,7]$ as well as $o b / o b$ and $d b / d b$ mice [8]. This increase has been detected early after weaning in $f a / f a$ rats, corresponding with the time when their obesity syndrome first becomes apparent [6]. Furthermore, chronic administration of exogenous NPY to specific hypothalamic nuclei or into the cerebral ventricles of normal rats results in many of the defects of obesity, including a marked increase in food intake, accelerated body weight gain, hypercorticosteronaemia and hyperinsulinaemia, leading to muscle insulin resistance with respect to glucose uptake, and increased triglyceride storage due to increased insulin responsiveness in white adipose tissue [9-16].

It is of note that hypercorticosteronaemia and hyperinsulinaemia are common features of many states of obesity associated with insulin resistance in rodents and in man [17-20], and these hormonal perturbations are of key importance in the NPY-induced obesity syndrome. Although previous studies have investigated the effects of NPY on the hypothalamo-pituitary-adrenal (HPA) axis and on insulin secretion after acute injection [3,21], little is known about the hormonal effects of chronic central NPY administration. Such knowledge would contribute to the understanding of the aetiology of obesity, considering the chronically elevated hypothalamic NPY levels associated with this pathology [6-8].

This work therefore aimed to characterise the time course of changes in secretion of corticosterone and insulin during 6 days of intracerebroventricular (i.c.v.) NPY infusion in normal rats, as well as the routes by which these two hormones are affected by central NPY.

\section{Materials and methods}

Animals. Lean heterozygous ( $\mathrm{Fa} / \mathrm{fa}$ ) female rats (9-12 weeks old) of the Zucker strain, bred in our laboratories, were housed individually under conditions of controlled temperature $\left(23^{\circ} \mathrm{C}\right)$ and illumination $(07.00-19.00$ hours $)$ and were provided with standard laboratory chow (Provimi Lacta, Cossonay, Switzerland) and tap water. All experiments were approved by the ethical committee for animal experimentation of the Geneva University Faculty of Medicine, as well as by the Swiss Federal and Geneva Cantonal Veterinarian Offices.

Placement of chronic jugular and intracerebroventricular (i.c.v.) cannulae. Under sodium pentobarbital anaesthesia (55 mg/kg i.p.; Siegfried, Zofingen, Switzerland), a catheter filled with 1.5:1 weight/volume polyvinylpyrrolidon (Merck, Darmstadt, Germany) in isotonic saline containing $250 \mathrm{IU} / \mathrm{ml}$ heparin (Liquemin; Roche Pharma, Reinach, Switzerland) and $10000 \mathrm{IU} / \mathrm{ml}$ penicillin (Hoechst-Pharma, Zurich, Switzerland) was placed in the right atrium via the jugular vein. A cannula was placed in the right lateral cerebral ventricle as previously described [22]. The jugular catheter was subcutaneously tunnelled to be externalised and fixed to the skull next to the i.c. v. cannula using dental cement (Paladur; Heraeus Kulzer
GmbH, Wehrheim, Germany). An i.m. injection of amoxicillin (50 mg/kg; Smith Kline Beecham, Thörishaus, Switzerland) was given, and animals were left for 7-10 days to recover from surgery, during which time they were handled daily and habituated to the blood-sampling procedure by thrice weekly rinsing of the jugular catheter with isotonic saline containing $25 \mathrm{IU} / \mathrm{ml}$ heparin and $20000 \mathrm{IU} / \mathrm{ml}$ penicillin.

I. c. v. infusion of neuropeptide $Y(N P Y)$. Porcine NPY $(15 \mu \mathrm{g} /$ day; Bachem, Bubendorf, Switzerland) or its vehicle for control rats $(0.04 \mathrm{~mol} / 1$ phosphate-buffered saline, $\mathrm{pH} 7.4$, with $0.2 \%$ bovine serum albumin (BSA) and $0.01 \%$ ascorbic acid) was i.c. v. infused for 6 days via a subcutaneously placed osmotic minipump (model 2001; Alza Corporation, Palo Alto, Calif., USA) as detailed elsewhere [22]. One group of NPY-infused rats and their controls were allowed to eat ad libitum. A second group of NPY-infused animals was pair-fed to the amount of food consumed by the vehicle-infused control rats in order to prevent NPY-induced hyperphagia. In this group, pellets were distributed at $07.45,12.00,17.30$ and 23.30 hours $(6,19,37.5$ and $37.5 \%$ of the daily food allowance of $22.0 \mathrm{~g}$, respectively). During i.c. v. infusion, food intake and body weight were measured daily, and a blood sample was collected from the jugular catheter into EDTA-coated tubes between 09.00 and 10.00 hours each day, $1-2 \mathrm{~h}$ after removal of food from cages. Food was replaced after blood sampling (ad libitum-fed rats), or at 12.00 hours (pair-fed rats). Plasma was stored at $20^{\circ} \mathrm{C}$ until measurement of basal hormone and metabolite concentrations.

Adrenocorticotropic hormone (ACTH) and corticosterone secretion induced by cold stress. An additional group of ad libitum-fed NPY-infused rats and their controls were exposed for $2 \mathrm{~h}$ to a temperature of $5^{\circ} \mathrm{C}$ between 10.30 and 12.30 hours on the second day after the start of i.c.v. infusion, as well as on the fourth day. A blood sample was collected prior to cold exposure as described above, and an additional sample was collected after the 2-h cold exposure for measurement of cold-induced plasma ACTH and corticosterone concentrations. Food was unavailable for $1-2 \mathrm{~h}$ before as well as during this experiment.

Insulin secretion induced by $i$. v. glucose injection. On day 4 or 5 after minipump implantation, an i.v. bolus of glucose $(300 \mathrm{mg} /$ $\mathrm{kg}$ ) was injected via the jugular catheter between $10.00-$ 11.30 hours. The catheter was rinsed with $0.5 \mathrm{ml}$ of isotonic saline, and a $2 \mathrm{ml}$ blood sample was collected between 1 and 3 min post-injection into tubes containing $40 \mu$ l EDTA $(24 \mathrm{mg} / \mathrm{ml}$ in isotonic saline, $\mathrm{pH} 7.4)$. Rats were immediately recompensed with $2 \mathrm{ml}$ of donor blood. This large volume of blood was necessary for subsequent high performance liquid chromatography (HPLC) of plasma for the assay of insulin, proinsulin and conversion intermediates.

Measurement of in vivo glucose utilisation during euglycaemichyperinsulinaemic clamps. After 6 days of i.c. v. infusion, pairfed NPY-infused rats and a vehicle-infused control group were fasted for 6-8 $\mathrm{h}$ and prepared for euglycaemic-hyperinsulinaemic clamps (using maximally effective plasma insulin concentrations) associated with the labelled 2-deoxyglucose technique to measure in vivo insulin-stimulated glucose utilisation index in individual tissues (diaphragm, quadriceps and gastrocnemius, separated into red and white components, soleus, tibialis, extensor digitorum longus, inguinal white adipose tissue) [14]. Uptake and phosphorylation of 2-deoxyglucose by various tissues during the clamp was estimated as described [14] and expressed as a glucose utilisation index ( $\mathrm{ng} / \mathrm{min} \times \mathrm{mg}$ 
tissue). Since the inguinal white adipose tissue weight of pairfed NPY-infused rats was significantly greater than that of control rats, the glucose utilisation index of this tissue was expressed in $\mathrm{ng} / \mathrm{min} \times \mu \mathrm{g}$ DNA (total DNA content of fat pad was unaltered by NPY infusion).

Measurement of hypothalamic corticotropin-releasing factor $(C R F)$-immunoreactivity. After 6 days of i.c. v. infusion, animals were killed by decapitation between 11.00 and 15.00 hours (3-7 $\mathrm{h}$ after removal of food from cages), the brain was removed, frozen on a cold table, and the hypothalamus was dissected and stored at $-80^{\circ} \mathrm{C}$ until measurement of total CRF immunoreactivity and protein content as published elsewhere [23, 24]. Pancreases were also removed, snap frozen in liquid nitrogen, and stored at $-80^{\circ} \mathrm{C}$ for later HPLC analysis of the different molecular forms of insulin.

Reverse-phase HPLC of plasma and pancreatic extracts. In the ad libitum-fed group of NPY-infused rats and their controls, plasma (collected after i.v. glucose injection) and pancreases were analysed by HPLC to determine the relative proportions of insulin, proinsulin, and their conversion intermediates. Pancreases were processed for HPLC as described by Schnetzler and colleagues [25]. Pancreatic extract $(700 \mu \mathrm{l})$ or $1-5 \mathrm{ml}$ of plasma (for controls, plasma from 6 rats was pooled due to low insulin concentrations) were purified on C18 Sep-Pak columns (Waters Associates, Milford, Mass., USA) as described [25]. We loaded 40-250 $\mu$ l of sample (containing $360 \mathrm{ng}$ immunoreactive insulin for pancreatic extracts and 6-12 ng for plasma samples) onto a Lichrosphere 100-RP-18 column, $4 \times 250 \mathrm{~mm}$ (Merck, Darmstadt, Germany) connected to a System Gold pump module 126 and detector module 166 (Beckman Instruments, Fullerton, Calif., USA). Elution buffers were: A) $50 \mathrm{mmol} / \mathrm{l}$ phosphoric acid, $20 \mathrm{mmol} / 1$ triethylamine and $50 \mathrm{mmol} / \mathrm{l}$ sodium perchlorate, $\mathrm{pH} \mathrm{3.0)}$ and $\mathrm{B}) 9: 1$ acetonitrile/water volume/volume. Insulin-like immunoreactive material was eluted at $1 \mathrm{ml} / \mathrm{min}$ and $38.5 \%$ buffer B from 0 $25 \mathrm{~min}$, followed by a linear increase in the proportion of buffer $\mathrm{B}$ to $42.5 \%$ between 25 and $95 \mathrm{~min}$. We collected $1 \mathrm{ml}$ fractions into glass tubes containing $100 \mu \mathrm{l} 0.5 \mathrm{~mol} / \mathrm{l}$ borate $/ 1 \%$ BSA, pH 9.2. Organic solvents in fractions were evaporated under vacuum, and lyophilised fractions were reconstituted in

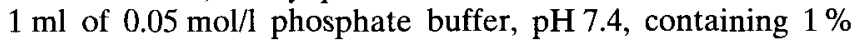
BSA, and stored at $-20^{\circ} \mathrm{C}$ until radioimmunoassay by the method of Herbert [11]. Peaks corresponding to mature insulin, proinsulin, and the conversion intermediates des 31,32and des 64,65-split proinsulin were identified by comparison with previously characterised standards [26].

Experiments involving vagotomised rats. Female SpragueDawley rats, bilaterally vagotomised (subdiaphragmatic) or sham-vagotomised at 8 weeks of age, were purchased from IFFA CREDO (L'Arbresle, France) and equipped with chronic jugular and i.c.v. cannulae as described above, using i.m. ketamin/xylazine anaesthesia (45 and $9 \mathrm{mg} / \mathrm{kg}$, respectively, Parke-Davis and Bayer AG, Leverkusen, Switzerland). At 12 weeks of age, rats were designated to one of four experimental groups: 1) sham-vagotomised + i.c.v. vehicle; 2) sham-vagotomised + i.c.v. NPY; 3) vagotomised + i.c.v. vehicle; 4) vagotomised + i.c.v. NPY. NPY or vehicle were i.c.v. infused as described above, and the food intake of all four groups was restricted to $22.0 \mathrm{~g}$ per day, the average amount consumed by sham-vagotomised and vagotomised rats prior to NPY infusion. Pellets were distributed as described for the pair-feeding protocol. Body weight, basal insulinaemia and glycaemia were measured daily as described for the other groups of rats. After 6 days of i.c.v. infusion, animals were fasted for 3-4h, anaesthetised with sodium pentobarbital $(55 \mathrm{mg} / \mathrm{kg}$, i. p.), and the carotid artery was cannulated. After $30 \mathrm{~min}$ a bolus of glucose $(300 \mathrm{mg} / \mathrm{kg})$ was injected via the carotid catheter, which was rinsed with $0.2 \mathrm{ml}$ of isotonic saline. At $0,5,10,20,30,40$, 60 and $90 \mathrm{~min}$ after glucose injection $150 \mu \mathrm{l}$ blood samples were collected into heparinised tubes for subsequent determination of plasma insulin and glucose concentrations. Integrated areas under the resultant insulin response curves were calculated (after subtracting baseline values) between $t=0$ and $t=60 \mathrm{~min}$ after glucose injection, when insulinaemia had returned to baseline values in all groups of rats. This integral is referred to as glucose-stimulated insulin output.

Plasma hormone measurements. Plasma corticosterone concentrations were measured by radioimmunoassay [11], and a kit from CIS Bio International (Gif-Sur-Yvette, France) was used for measurement of plasma ACTH. Insulinaemia was measured by radioimmunoassay [11] using guinea pig anti-rat insulin serum (Linco Research Inc., St. Louis, Mo. USA). Plasma glucose concentrations were determined using a kit from Boehringer (Mannheim, Germany).

Statistical analysis. For the daily measurements of food intake, body weight, change in body weight, basal plasma ACTH, corticosterone, insulin and glucose concentrations, differences in normal and vagotomised rats were assessed by one-way analysis of variance (ANOVA) with repeated measures followed by post-hoc Duncan's range tests. When two groups were found to be significantly different from each other, multiple Bonferroni comparisons were made to locate differences at each time point. Plasma ACTH and corticosterone concentrations before and after cold exposure (in ad libitum-fed NPY-infused and control rats) were compared by the Kruskal-Wallis nonparametric ANOVA test followed by Dunn's multiple comparisons tests in order to detect differences between the two groups of rats under basal or stimulated conditions, as well as differences within groups of rats induced by cold stress. Hypothalamic levels of CRF immunoreactivity in the three groups of rats were compared by one-way ANOVA followed by a Student-Newman-Keuls multiple comparisons test. Glucose-stimulated insulin output was compared between sham-vagotomised and vagotomised rats (i.c.v. infused with vehicle or NPY) by one-way ANOVA and Student-Newman Keuls multiple comparisons. Differences between control and NPY-infused rats with respect to glucose utilisation index of various tissues and inguinal white adipose tissue weight were made by one-tailed Student's $t$-tests. For all analyses, values of $p<0.05$ were accepted as being statistically significant.

\section{Results}

Effect of 6-day i.c.v. NPY infusion on feeding and body weight gain. I.c.v. NPY infusion caused a marked increase in ad libitum food intake which was sustained for the 6 days of its infusion. Food intake on day 6 was $52 \pm 7 \mathrm{~g}$ in NPY-infused rats compared to $19.1 \mathrm{~g}$ for controls $(n=6-15, p<0.001)$. The food intake of pair-fed NPY infused rats was restricted to $22.0 \mathrm{~g}$ per day as described under Materials and Methods. The body weight gain of ad libitum-fed NPY-infused rats was significantly greater than that of control rats $(27.4 \pm 4.3 \mathrm{~g} / 6$ days vs $7.9 \pm 2.0 \mathrm{~g} / 6$ days, $n=6-15, p<0.001$ ) whereas the body weight 

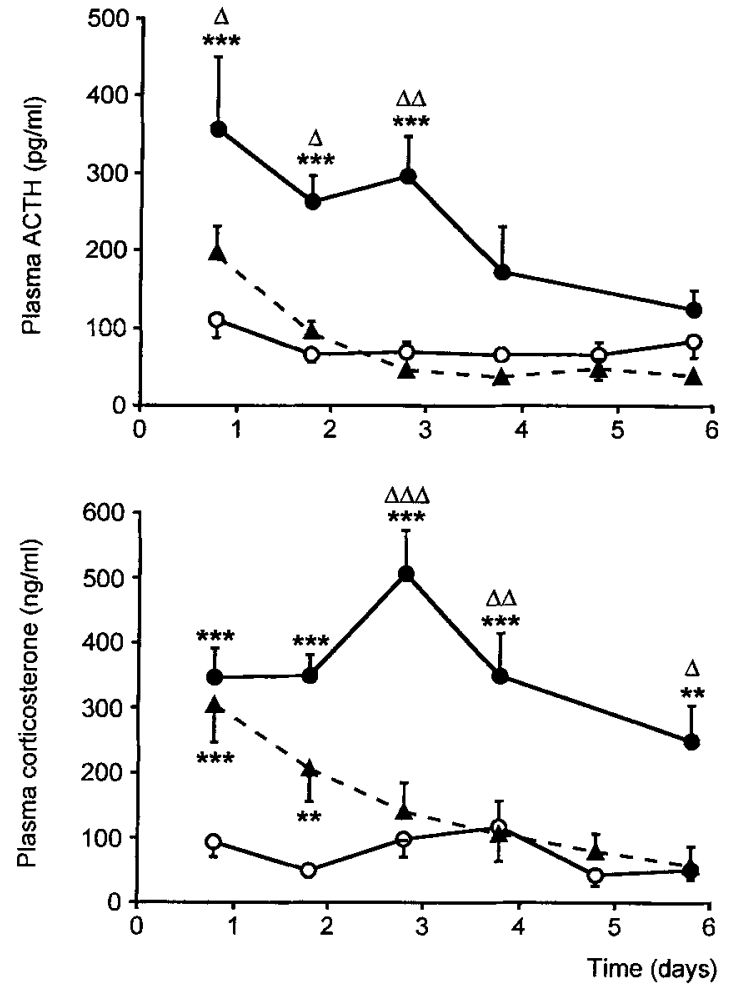

Fig. 1. Basal plasma ACTH (upper panel) and corticosterone (lower panel) concentrations during i.c.v. infusion of NPY $(15 \mu \mathrm{g} /$ day $)$ in normal rats allowed to eat ad libitum, or pairfed with vehicle-infused controls ( $\bullet$, NPY ad libitum-fed; $\boldsymbol{\Delta}$, NPY pair-fed; $O$, vehicle-infused controls). Plotted values are means \pm SEM of $6-15$ rats per group. $* * p<0.01$ and $* * * p<0.001$ vs corresponding value of vehicle-infused control rats. $\Delta p<0.05 ; \Delta \Delta p<0.01$ and $\Delta \Delta \Delta p<0.001$ vs corresponding value of pair-fed NPY-infused rats

gain of pair-fed NPY-infused rats was no different from that of the control group.

Effect of 6-day i.c.v. NPY infusion on the hypothalamo-pituitary adrenal (HPA) axis. In animals allowed to eat ad libitum, i.c.v. NPY infusion caused significant elevations in plasma ACTH levels compared to control values during the first 3 days of infusion (Fig. 1 upper panel). However, this effect of NPY was not sustained with continued infusion of the peptide; within 4-6 days of NPY infusion in ad libitum-fed rats, plasma ACTH levels were not significantly different from those of control rats. In the same manner, plasma ACTH levels of pair-fed NPY-infused rats tended to be higher than those of control rats during the first day of NPY infusion, but were similar to control values during the remaining 5 days of peptide infusion.

Compared to control values, plasma corticosterone levels were significantly increased by i.c.v. NPY infusion in both ad libitum- and pair-fed rats (Fig. 1, lower panel). However, whereas Figure 1 shows that the hypercorticosteronaemia of ad libitum-fed NPYinfused rats remained present during the entire 6day infusion period, that of pair-fed NPY-infused

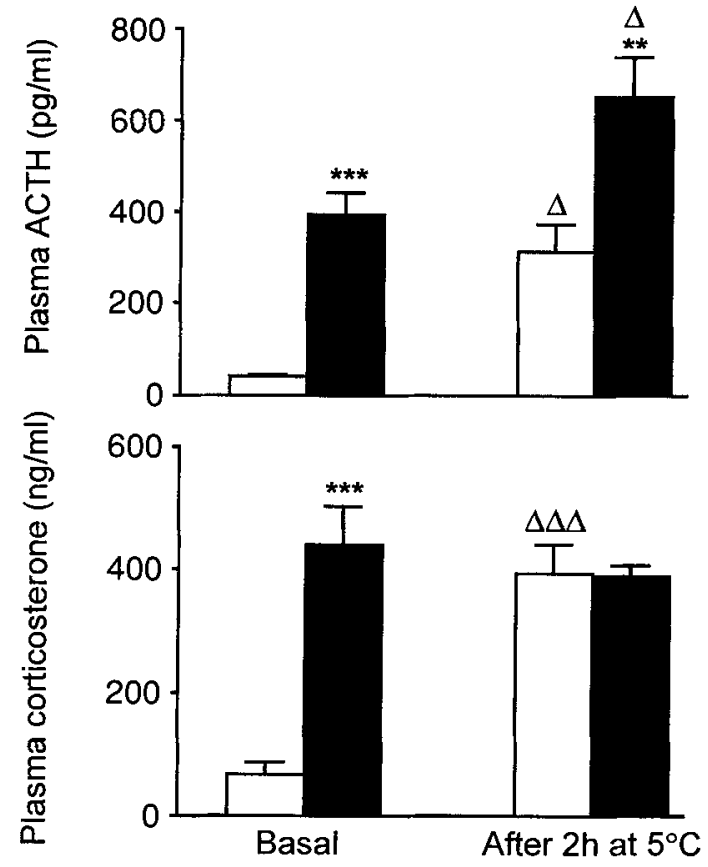

Fig. 2. Plasma ACTH (upper panel) and corticosterone (lower panel) concentrations under basal conditions and after $2 \mathrm{~h}$ at $5^{\circ} \mathrm{C}$, measured after 2 days of i.c.v. infusion of NPY ( $\square$, $15 \mu \mathrm{g} /$ day) or vehicle for control rats ( $\square$ ). All animals were allowed to eat ad libitum, but food was unavailable for $1-2 \mathrm{~h}$ prior to basal blood sampling and during cold exposure. Plotted values are means \pm SEM of $8-9$ rats per group. $* * p<0.01$ and $* * * p<0.001$ vs corresponding value of vehicle-infused control rats. $\Delta p<0.05$ and $\Delta \Delta \Delta p<0.001$ vs basal value of the corresponding group

rats was normalised from the third day of NPY infusion onwards.

Figure 2 further shows that after 2 days of i.c.v. NPY infusion with ad libitum feeding, both basal plasma ACTH and corticosterone concentrations were considerably greater than the corresponding values of control rats. Plasma ACTH concentrations were further increased, in both control and NPY-infused rats, after $2 \mathrm{~h}$ of cold exposure $\left(5^{\circ} \mathrm{C}\right)$ relative to their respective basal $\left(23^{\circ} \mathrm{C}\right)$ values. The cold stress-induced plasma concentrations of ACTH were much greater in NPY-infused rats than in control rats. The cold exposure also caused a marked increase in plasma corticosterone concentrations of control rats. In NPY-infused rats, the high plasma corticosterone concentrations measured under basal conditions were not further increased by cold exposure, presumably because they had already reached maximum plateau values under basal conditions.

On day 4, the same cold exposure in control rats still caused increases in plasma concentrations of ACTH and corticosterone, while this failed to occur in ad libitum-fed NPY-infused rats (data not shown).

After 6 days of i.c.v. NPY infusion, the quantity of corticotropin-releasing factor (CRF)-immunoreactivity in the hypothalamus was significantly reduced 


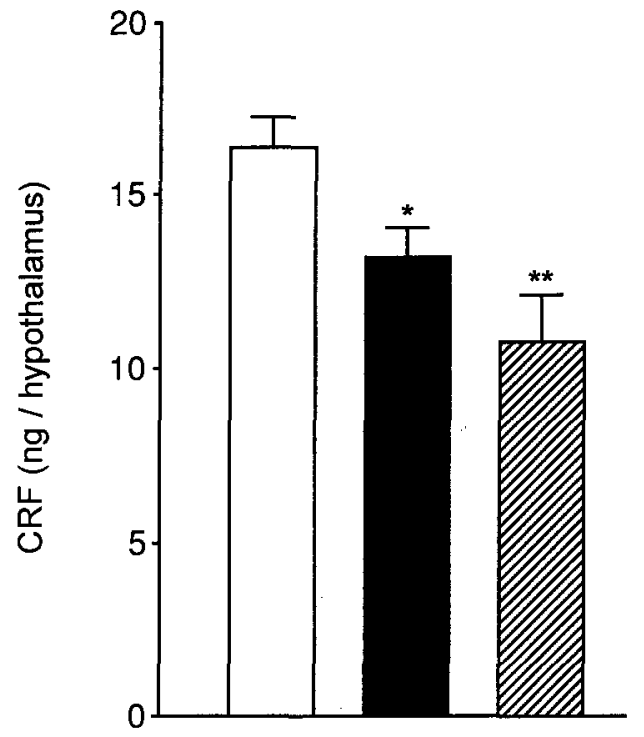

Fig. 3. Hypothalamic content of CRF immunoreactivity after 6 days of i.c. v. infusion of NPY $(15 \mu \mathrm{g} /$ day $)$ in normal rats allowed to eat ad libitum, or pair-fed with vehicle-infused con-

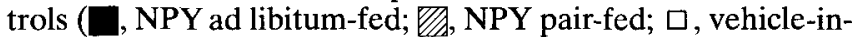
fused controls). Plotted values are means \pm SEM of 6-10 rats per group. ${ }^{*} p<0.05$ and ${ }^{* *} p<0.01$ vs control rats

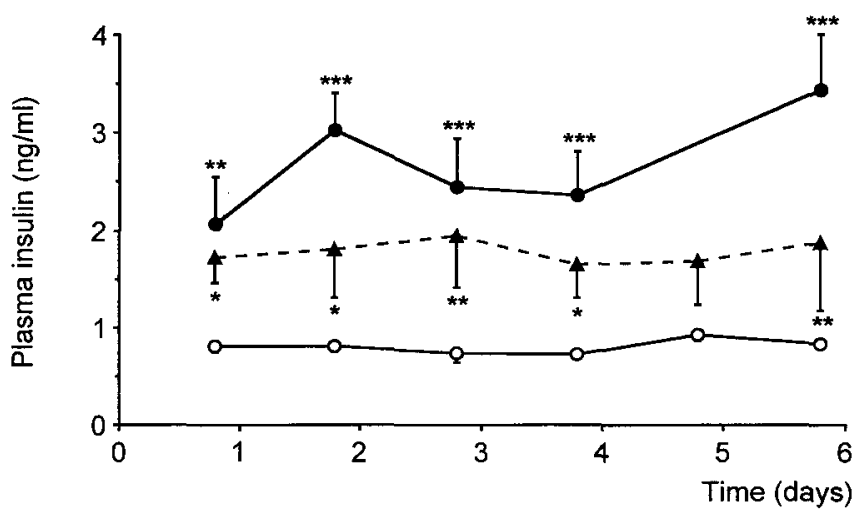

Fig.4. Basal plasma insulin concentrations during i.c. v. infusion of NPY $(15 \mu \mathrm{g} /$ day $)$ in normal rats allowed to eat ad libitum, or pair-fed with vehicle-infused controls ( , NPY ad libitum-fed; $\boldsymbol{\Delta}$, NPY pair-fed; $O$, vehicle-infused controls). Plotted values are means \pm SEM of $6-15$ rats per group. $* p<0.05$; ** $p<0.01$ and ${ }^{* * *} p<0.001$ vs corresponding value of vehicle-infused control rats

relative to control values (Fig. 3). This decrease in hypothalamic CRF content was observed in both pairfed and in ad libitum-fed NPY-infused rats, and the difference between the two groups of NPY-infused rats was not significant. There was no difference between the three groups of rats shown in Figure 3 with respect to total protein content per hypothalamus (data not shown).

Effect of 6-day i.c.v. NPY infusion on insulin output. Chronic i.c.v. NPY infusion resulted in significant increases in basal insulinaemia in both ad libitum-fed rats and in rats that were pair-fed with vehicle-infused controls (Fig.4). This NPY-induced hyperinsulinaemia was present after 1 day of i.c. v. NPY infusion and was sustained during the entire 6 days of NPY infusion.

In addition to basal hyperinsulinaemia, insulin secretion in response to i. v. glucose injection $(300 \mathrm{mg} /$ $\mathrm{kg}$ ) was also increased in rats infused with NPY (ad libitum- or pair-fed) compared with vehicle-infused control rats (data not shown). This is despite the fact that plasma glucose concentrations were increased to identical values in all groups of rats by the i. v. glucose bolus.

The above-mentioned levels of basal and stimulated insulinaemia represent measures of total insulinlike immunoreactivity in plasma, which includes not only mature insulin but also proinsulin, and the conversion intermediates des 64,65- and des 31,32-split proinsulin [27]. These intermediates are formed by endoproteolytic cleavage at the A-chain/C-peptide and the B-chain/C-peptide junctions of proinsulin, respectively, followed by enzymatic trimming of residual C-terminal basic amino acids [27]. To determine whether the composition of total insulin-like immunoreactivity in plasma after i.v. glucose stimulation was altered by i.c.v. NPY infusion, a plasma sample collected 1-3 min after a bolus glucose injection was fractionated by HPLC prior to radioimmunoassay. In ad libitum-fed NPY-infused rats as in control rats, mature insulin contributed to over $90 \%$ of the total plasma insulin-like immunoreactivity, the remaining being made up of proinsulin and conversion intermediates (data not shown). Six days of i.c. v. NPY infusion in ad libitum-fed rats had no effect on either the wet weight of the pancreas, or on the total quantity of insulin-like immunoreactivity in the pancreas (Table 1). The composition of total pancreatic insulin-like immunoreactivity was no different in NPYtreated rats compared to control rats, with over $94 \%$ of the pancreatic insulin-like immunoreactivity being due to mature insulin in both cases, intact proinsulin, des 64,65- and des 31,32-split proinsulin making up the remaining $6 \%$ (Table 1 ).

Metabolic consequences of 6-day i.c.v. NPY infusion with pair-feeding regime. As shown in Figure 5, the insulin-stimulated glucose utilisation index of muscles measured during euglycaemic-hyperinsulinaemic clamps was decreased after 6 days of i.c.v. NPY infusion with pair-feeding to control rats, indicating muscle insulin resistance. NPY infusion tended to also cause a decrease in insulin-stimulated glucose utilisation index in other muscles studied and not shown in the figure, although the intergroup difference was not statistically significant. In contrast, the glucose utilisation index of inguinal white adipose tissue was significantly increased after 6 days of central NPY administration with pair-feeding (Fig.5). Inguinal 
Table 1. Effect of 6-day i.c.v. NPY infusion (15 $\mu \mathrm{g} /$ day) on pancreas weight, total insulin content, and relative proportions of insulin biosynthetic products in the pancreas

\begin{tabular}{lcc}
\hline & Control & i.c.v. NPY \\
\hline Wet weight of pancreas (g) & $0.68 \pm 0.06$ & $0.74 \pm 0.04$ \\
Total insulin-like immunoreactivity & & \\
per pancreas $(\mu \mathrm{g})$ & $24.7 \pm 5.1$ & $32.1 \pm 5.1$ \\
\% Mature insulin & $95.2 \pm 1.0$ & $94.1 \pm 0.8$ \\
\% des 31,32-split proinsulin & $2.5 \pm 0.7$ & $3.1 \pm 0.5$ \\
\% des 64,65-split proinsulin & $0.7 \pm 0.05$ & $0.8 \pm 0.05$ \\
\% Proinsulin & $1.6 \pm 0.2$ & $2.0 \pm 0.3$ \\
\hline
\end{tabular}

All animals were allowed to eat ad libitum during the i.c.v. infusion. Values are means \pm SEM of 3-7 rats per group. There was no significant difference between control and NPY-infused rats

white adipose tissue weight was significantly greater in pair-fed NPY-infused rats than in control rats $(1.4 \pm 0.2 \mathrm{~g}$ vs $1.0 \pm 0.1 \mathrm{~g}, n=5-6, p<0.05)$. When ad libitum-fed during 6-day i.c.v. NPY infusion, this increase in inguinal white adipose tissue weight was more pronounced $(2.4 \pm 0.2 \mathrm{~g}$ vs $1.1 \pm 0.2 \mathrm{~g}$ in vehicle-infused controls, $n=5-7, p<0.005)$.

Impact of vagotomy on i.c. v. NPY-induced insulin output. For these experiments, the food intake of all four groups of rats (sham-vagotomised and vagotomised, i.c.v. infused with vehicle or NPY) was restricted to that of vehicle-infused rats $(22.0 \mathrm{~g}$ per day). Such pair feeding was important because substrate- and vagus nerve-mediated insulin output are influenced by substrate availability [28]. There was no significant difference between the four groups of rats with respect to absolute body weight, body weight gain, or basal glycaemia during the 6-day infusion period.

The mean basal insulinaemia measured during 6 days of i.c.v. infusion of vehicle or NPY in sham-vagotomised rats or rats with bilateral subdiaphragmatic vagotomy are shown in Figure 6. I.c.v. NPY infusion produced a significant increase in the basal insulinaemia of sham-vagotomised rats, but had no effect on the basal insulinaemia of vagotomised rats. As further shown by Figure 6, i.v. glucose-stimulated insulin output was considerably increased by i.c. v. NPY infusion in sham-vagotomised rats, but was unaffected by i.c. v. NPY in vagotomised animals. Note that the glycaemic response in the $90 \mathrm{~min}$ after i. v. glucose injection was identical in the four groups of rats shown in Figure 6.

\section{Discussion}

The aim of this study was to characterise the longitudinal changes in activity of the hypothalamo-pituitary-adrenal (HPA) axis and in insulin secretion
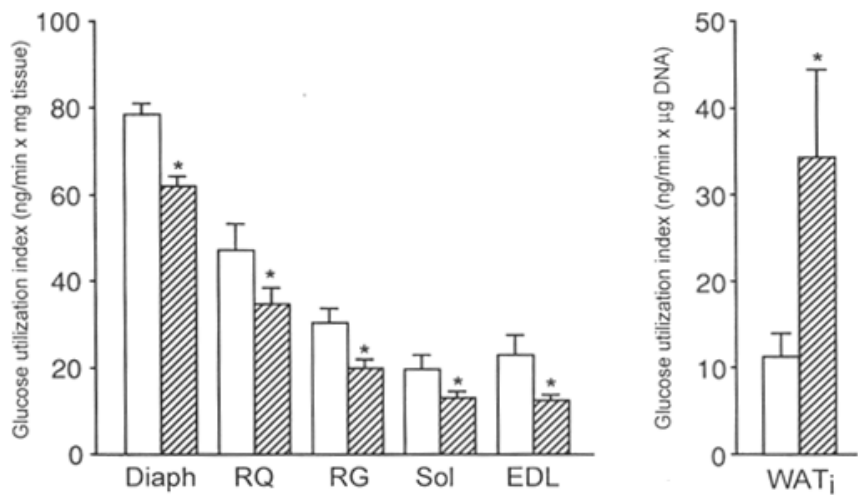

Fig.5. Glucose utilisation index of various muscles (Diaph, diaphragm; RQ, red quadriceps; RG, red gastrocnemius; Sol, soleus; EDL, extensor digitorum longus) and of inguinal white adipose tissue (WATi), measured during euglycaemic-hyperinsulinaemic clamps after 6 days of i.c. v. infusion of NPY $(15 \mu \mathrm{g} /$ day) in normal rats that were pair-fed with vehicle-infused controls (泡, NPY pair-fed; $\square$, vehicle-infused controls). Plotted values are means \pm SEM of $5-6$ rats per group. ${ }^{*} p<0.05$ vs corresponding value of control rats
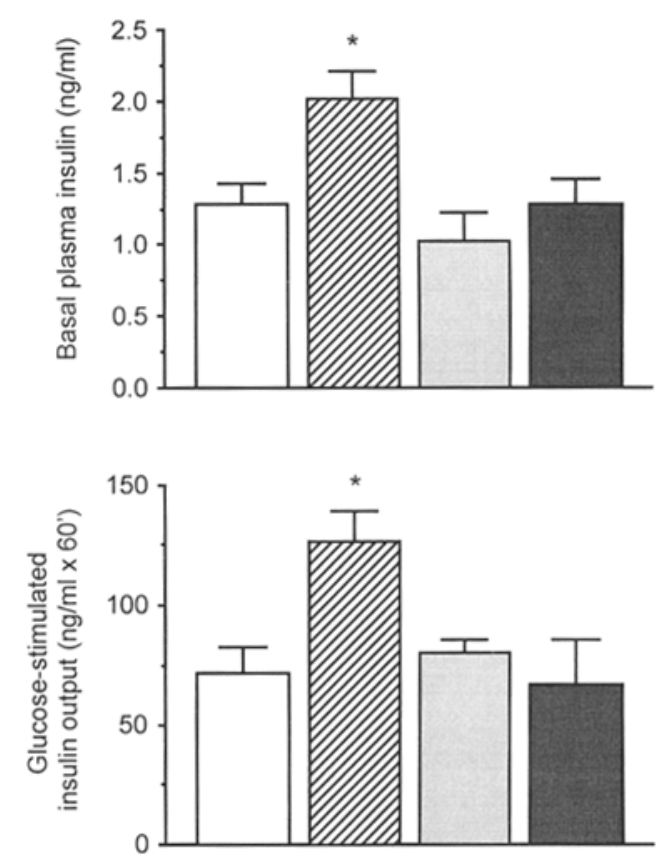

Fig. 6. Basal plasma insulin concentrations (upper panel) and insulin output after an i. v. bolus injection of $300 \mathrm{mg} / \mathrm{kg}$ glucose (lower panel) during i.c. v. infusion of NPY (15 $\mu$ g/day) in sham-vagotomised or vagotomised rats compared to vehicleinfused sham or vagotomised rats $(\square$, vehicle-infused sham vagotomised; 2 NPY sham-vagotomised; $\square$ vehicle-infused vagotomised; $\square$ NPY vagotomised). Food intake of all animals was restricted to $22.0 \mathrm{~g} / \mathrm{day}$ (pair-feeding). Plotted values are means $\pm S E M$ of $4-6$ rats per group. $* p<0.05$ vs vehicle-infused sham-vagotomised rats

during 6 days of intracerebroventricular (i.c. v.) infusion of neuropeptide Y (NPY) in normal rats, and to determine the impact of subdiaphragmatic vagotomy on NPY-induced insulin secretion. 
Past research has shown that acute injection of NPY into the cerebral ventricles or into the hypothalamic paraventricular nucleus (PVN) stimulates the HPA axis of several species [3]. Such NPY-induced changes include increases in corticotropin-releasing factor (CRF) mRNA levels and immunoreactivity in the PVN $[29,30]$, and increases in plasma adrenocorticotropic hormone (ACTH) and corticosterone concentrations [3]. In vitro, NPY stimulates CRF secretion from hypothalamic fragments [3], and it may also increase the sensitivity of cultured pituitary cells to CRF-induced secretion of ACTH [3], although this has not been a unanimous finding $[31,32]$. There is some evidence that endogenous NPY may influence the activity of the HPA axis in vivo, since NPYergic nerve terminals have been shown to make contact with CRF-synthesising perikaryon of the PVN [3], and since i.c. v. infusion of anti-NPY serum eliminated the stress-induced increase in plasma ACTH concentrations in dogs [3].

In the present study it was shown that NPY stimulated the basal and stress-induced activity of the HPA axis during the first 2 days of its i.c.v. infusion. Although feeding is known to increase plasma ACTH and corticosterone concentrations [33], this effect of i.c.v. NPY infusion was not simply due to the associated increase in food intake (hyperphagia), since it was observed, albeit to a lesser extent, even when NPY-induced hyperphagia was prevented by a pair-feeding regime. However, after 4 to 6 days of continuous i.c. v. NPY administration, basal plasma concentrations of ACTH and corticosterone were normalised or tending towards normal control values, there was no change in their plasma concentrations in response to stress, and the hypothalamic content of CRF-immunoreactivity was reduced relative to control values. These findings suggest that chronic central NPY administration ultimately inhibits the activity of the HPA axis. One possible explanation for this is that the NPY $Y_{1}$ receptor, which is thought to be responsible for the effects of NPY on the HPA axis [34], may be down-regulated in the face of 6-day exposure to its agonist, while such down- regulation would not occur for the NPY $\mathrm{Y}_{5}$ receptor, responsible for the effect of NPY on food intake [35]. An additional possibility is that the elevated plasma concentrations of corticosterone during the first few days of i.c. v. NPY infusion could inhibit the activity of the HPA axis by feedback inhibition of CRF and ACTH secretion $[36,37]$. The latter scenario is presently favoured since it would explain not only the normalisation of basal plasma ACTH and corticosterone levels observed after several days of central NPY administration, but also the total lack of stress-induced secretion of these hormones at this time, as well as the decrease in hypothalamic CRF-immunoreactivity [37]. These data suggest that the hypercorticism of genetically obese rodents [19] may not be caused by the associated increase in hypothalamic NPY-ergic activity, and other routes, such as increases in arginine vasopressin regulation of the HPA axis [38], need to be investigated.

Although the effects of acute central NPY injection on insulin secretion are small or absent, as studied and reviewed [21], a sustained increase in basal insulinaemia was apparent during chronic (6 days) central NPY infusion in normal rats. This effect of NPY, which is in agreement with reports of others $[10,11]$, was manifest after just 1 day of its i.c. v. infusion. It was present both in animals that were ad libitum-fed during central NPY infusion, as well as in those that were pair-fed along with vehicle-infused control rats, demonstrating that this hyperinsulinaemia was not simply a consequence of NPY-induced hyperphagia. The basal hyperinsulinaemia of rats infused with NPY was accompanied by a hypersecretion of insulin in response to stimuli such as i. v. injection of glucose as presently shown, or ingestion of a meal [12].

In patients with non-insulin-dependent diabetes mellitus (NIDDM), increases in the absolute or relative amounts of proinsulin in the plasma (compared to plasma concentrations of mature insulin) are encountered [39-41]. It is hypothesised that the chronic stimulation of insulin secretion in NIDDM patients leads to an increased output of immature insulin secretory granules in which the ratio of proinsulin and conversion intermediates to insulin is higher than that of mature granules [27, 40, 41]. It was therefore of interest to study proinsulin secretion in an animal model presenting sustained hyperstimulation of insulin secretion. In the present study, rats i.c.v. infused with NPY for 6 days, although hyperinsulinaemic, show no evidence of perturbations in the molecular forms of secreted insulin and related peptides, or in the relative proportions of these molecules in the pancreas. It must therefore be concluded that increased insulin turnover in the beta cell per se, as in the present model, does not necessarily lead to any perturbation in proinsulin conversion.

This work shows for the first time, using pair-feeding conditions to completely abolish NPY-induced hyperphagia, that 6 days of central NPY infusion resulted in a state of insulin resistance in muscles (as indicated by reduced 2-deoxyglucose uptake and phosphorylation relative to control rats) and a hyperresponsiveness of such insulin-induced glucose uptake and phosphorylation in white adipose tissue. Although such changes in peripheral glucose metabolism have been observed in freely feeding, hyperphagic i.c. v. NPY-infused rats [12-14], the present data show that even in the absence of an increase in substrate supply, central NPY infusion placed the animals in a "thrifty" phenotype channelling glucose carbon away from utilisation and into lipid accretion pathways. This is reflected by the increases in inguinal 
white adipose tissue weight of both pair-fed and ad libitum-fed NPY-infused rats compared to controls. These metabolic effects of chronic i.c.v. NPY infusion may be a consequence of the transient hypercorticosteronaemia [15] and especially the sustained hyperinsulinaemia [16] presently reported under both ad libitum- and pair-feeding conditions.

Finally, the present investigation demonstrates that i.c.v. NPY infusion increases basal and stimulated insulinaemia via activation of the vagus nerve, since bilateral subdiaphragmatic vagotomy prevented such NPY-induced increases in insulinaemia. Similarly, other effects of central NPY injection on the gastrointestinal tract (such as increases in gastric acid, bile and pepsin secretion) are mediated by vagal cholinergic pathways [42]. Recent work from this laboratory [14] has shown that adrenalectomy is able to prevent hyperinsulinaemia during chronic central NPY infusion in rats. Other investigators have shown that the insulin hypersecretion of genetically obese $f a / f a$ rats, which present spontaneously elevated hypothalamic NPY expression [6], can be abolished by adrenalectomy, restored by i.c. v. or peripheral glucocorticoid replacement, and subsequently blocked by the cholinergic antagonist atropine [43, 44]. It was concluded that glucocorticoids play a permissive role in the parasympathetically mediated hyperinsulinaemia of $f a / f a$ rats. These data collectively suggest that high NPY levels in the hypothalami of genetically obese rodents stimulate insulin secretion by activating parasympathetic efferents to the pancreas, the preganglionic neurones of which are mainly located in the dorsal motor nucleus of the vagus [45], and that this effect of NPY is dependent on circulating glucocorticoids, probably acting within the central nervous system.

In summary, chronic central NPY infusion resulted in transient activation of the HPA axis followed by an eventual inhibition of this axis, and a sustained, vagally mediated increase in basal and substrate-induced insulinaemia. Considering the key role of insulin in metabolic homeostasis [16], further work aimed at understanding how NPY activates vagal efferents to the pancreas, and the role of glucocorticoids in this process, could contribute to our knowledge of the metabolic defects associated with obesity syndromes in which NPY expression in the hypothalamus is chronically elevated.

Acknowledgements. This study was supported by grants 32 40806.94 (B. J.), 31-40839.94 (P.A.H.), and 31-039749.93/1 (R.C.G.) of the Swiss National Science Foundation (Bern, Switzerland) and a grant-in-aid of E.Lilly and Company (B.J., Indianapolis, Indiana, USA). We wish to thank Ms. P. Arboit and Ms. I. Antoni for expert technical assistance, and Ms. F. Touabi for secretarial help. Mr. P. Germann, Mr. A. Volery, and Mr. D. Châtelain are also acknowledged for their technical expertise necessary for the realisation of this work.

\section{References}

1. Hendry SHC (1993) Organization of neuropeptide Y neurons in the mammalian central nervous system. In: Colmers WF, Wahlestedt C (eds) The biology of neuropeptide $\mathrm{Y}$ and related peptides. Humana Press Inc, New Jersey, pp 65-156

2. Ergene E, Dunbar JC, Barraco RA (1993) Visceroendocrine responses elicited by neuropeptide $\mathrm{Y}$ in the nucleus tractus solitarius. Brain Res Bull 32: 461-465

3. McDonald JK, Koenig JI (1993) Neuropeptide Y actions on reproductive and endocrine functions. In: Colmers WF, Wahlestadt C (eds) The biology of neuropeptide $Y$ and related peptides. Humana Press Inc, New Jersey, pp 419 456

4. Stanley BG (1993) Neuropeptide Y in multiple hypothalamic sites controls eating behavior, endocrine, and autonomic systems for body energy balance. In: Colmers WF, Wahlestedt $\mathrm{C}$ (eds) The biology of neuropeptide $\mathrm{Y}$ and related peptides. Humana Press Inc, New Jersey, pp 457-509

5. Dryden S, Frankish H, Wang Q, Williams G (1994) Neuropeptide $Y$ and energy balance: one way ahead for the treatment of obesity? Eur J Clin Invest 24: 293-308

6. Bchini-Hooft van Huijsduijnen $O$, Rohner-Jeanrenaud F, Jeanrenaud B (1993) Hypothalamic neuropeptide Y messenger ribonucleic acid levels in pre-obese and genetically obese (fa/fa) rats; potential regulation thereof by corticotropin-releasing factor. J Neuroendocrinol 5: 381-386

7. Williams G, Shellard L, Lewis DE et al. (1992) Hypothalamic neuropeptide $\mathrm{Y}$ disturbances in the obese $(\mathrm{cp} / \mathrm{cp})$ JCR : LA corpulent rat. Peptides 13: 537-540

8. Stephens TW, Basinski M, Bristow PK et al. (1995) The role of neuropeptide $\mathrm{Y}$ in the antiobesity action of the obese gene product. Nature 377: 530-532

9. Stanley BG, Kyrkouli SE, Lampert S, Leibowitz SF (1986) Neuropeptide Y chronically injected into the hypothalamus: a powerful neurochemical inducer of hyperphagia and obesity. Peptides 7: 1189-1192

10. Billington CJ, Briggs JE, Harker S, Grace M, Levine AS (1994) Neuropeptide $Y$ in hypothalamic paraventricular nucleus: a center coordinating energy metabolism. Am J Physiol 266: R1765-R1770

11. Zarjevski N, Cusin I, Vettor R, Rohner-Jeanrenaud F, Jeanrenaud B (1993) Chronic intracerebroventricular neuropeptide-Y administration to normal rats mimics hormonal and metabolic changes of obesity. Endocrinology 133 : $1753-1758$

12. Zarjevski N, Cusin I, Vettor R, Rohner-Jeanrenaud F, Jeanrenaud $B$ (1994) Intracerebroventricular administration of neuropeptide $Y$ to normal rats has divergent effects on glucose utilization by adipose tissue and skeletal muscle. Diabetes 43: 764-769

13. Vettor R, Zarjevski N, Cusin I, Rohner-Jeanrenaud F, Jeanrenaud B (1994) Induction and reversibility of an obesity syndrome by intracerebroventricular neuropeptide $\mathrm{Y}$ administration to normal rats. Diabetologia 37: 1202-1208

14. Sainsbury A, Cusin I, Rohner-Jeanrenaud F, Jeanrenaud B (1997) Adrenalectomy prevents the obesity syndrome produced by chronic central neuropeptide $\mathrm{Y}$ infusion in normal rats. Diabetes 46: 209-214

15. Guillaume-Gentil C, Assimacopoulos-Jeannet F, Jeanrenaud B (1993) Involvement of non-esterified fatty acid oxidation in glucocorticoid-induced peripheral insulin resistance in vivo in rats. Diabetologia 36: 899-906

16. Cusin I, Terrettaz J, Rohner-Jeanrenaud F, Zarjevski N, Assimacopoulos-Jeannet F, Jeanrenaud B (1990) Hyperinsulinemia increases the amount of GLUT4 mRNA in white adipose tissue and decreases that of muscles: a clue for 
increased fat depot and insulin resistance. Endocrinology 127: $3246-3248$

17. Coleman DL (1988) Classical diabetes models: past lessions and potential new therapies. In: Shafrir E, Renold $\mathrm{AE}$ (eds) Frontiers in diabetes research. Lessons from animal diabetes II. John Libbey \& Co Ltd, London, pp 253256

18. Nosadini R, Del Prato S, Tiengo A et al. (1983) Insulin resistance in Cushing's syndrome. J Clin Endocrinol Metab 57: 529-536

19. Guillaume-Gentil C, Rohner-Jeanrenaud F, Abramo F, Bestetti GE, Rossi GL, Jeanrenaud B (1990) Abnormal regulation of the hypothalamo-pituitary-adrenal axis in the genetically obese fa/fa rat. Endocrinology 126: 1873 1879

20. Jeanrenaud B (1991) Neuroendocrinology and evolutionary aspects of experimental obesity. In: Oomura Y, Tarui $\mathrm{S}$, Inoue S, Shimazu T (eds) Progress in obesity research 1990. John Libbey, Cornwall, pp 409-421

21. Sainsbury A, Rohner-Jeanrenaud F, Grouzmann E, Jeanrenaud B (1996) Acute intracerebroventricular administration of neuropeptide $\mathrm{Y}$ stimulates corticosterone output and feeding but not insulin output in normal rats. Neuroendocrinology 63 : 318-326

22. Rohner-Jeanrenaud F, Walker CD, Greco-Perotto R, Jeanrenaud $B$ (1989) Central corticotropin-releasing factor administration prevents the excessive body weight gain of genetically obese (fa/fa) rats. Endocrinology 124: 733-739

23. Hadid R, Spinedi E, Daneva T, Grau G, Gaillard RC (1995) Repeated endotoxin treatment decreases immune and hypothalamo-pituitary-adrenal axis responses: effects of orchidectomy and testosterone therapy. Neuroendocrinology 62: 348-355

24. Spinedi E, Giacomini M, Jacquier MC, Gaillard RC (1991) Changes in the hypothalamo-corticotrope axis after bilateral adrenalectomy: evidence for a median eminence site of glucocorticoid action. Neuroendocrinology 53: 160-170

25. Schnetzler B, Murakawa G, Abalos D, Halban P, Selden R (1993) Adapatation to supraphysiologic levels of insulin gene expression in transgenic mice: evidence for the importance of posttranscriptional regulation. J Clin Invest 92: $272-280$

26. Sizonenko S, Halban PA (1991) Differential rates of conversion of rat proinsulin I and II: evidence for slow cleavage at the B-chain/C-peptide junction of proinsulin II. Biochem J 278: 621-625

27. Halban PA (1991) Structural domains and molecular lifestyles of insulin and its precursors in the pancreatic beta cell. Diabetologia 34: 767-778

28. Woods SC, Porte DJr (1974) Neural control of the endocrine pancreas. Physiol Rev 54: 596-619

29. Suda T, Tozawa F, Iwai I et al. (1993) Neuropeptide-Y increases the corticotropin-releasing factor messenger ribonucleic acid level in the rat hypothalamus. Mol Brain Res 18: 311-315

30. Haas DA, George SR (1987) Neuropeptide Y administration acutely increases hypothalamic corticotropin-releasing factor immunoreactivity: lack of effect in other rat brain regions. Life Sci 41: 2725-2731

31. Brooks AN, Howe DC, Porter DWF, Naylor AM (1994) Neuropeptide-Y stimulates pituitary-adrenal activity in fetal and adult sheep. J Neuroendocrinol 6: 161-166

32. Liu JP, Clarke IJ, Funder JW, Engler D (1994) Studies of the secretion of corticotropin-releasing factor and arginine vasopressin into the hypophysial-portal circulation of the conscious sheep II. The central noradrenergic and neuropeptide $\mathrm{Y}$ pathways cause immediate and prolonged hypothalamic-pituitary-adrenal activation. Potential involvement in the pseudo-Cushing's syndrome of endogenous depression and anorexia nervosa. J Clin Invest 93: 1439-1450

33. Dallman MF, Strack AM, Akana SF et al. (1993) Feast and famine: critical role of glucocorticoids with insulin in daily energy flow. Front Neuroendocrinol 14: 303-347

34. Miura M, Inui A, Teranishi A et al. (1992) Structural requirements for the effects of neuropeptide Y on the hypothalamic-pituitary-adrenal axis in the dog. Neuropeptides 23: $15-18$

35. Gerald C, Walker MW, Criscione L et al. (1996) A receptor subtype involved in neuropeptide-Y-induced food intake. Nature 382: 168-171

36. Brück K (1983) Functions of the endocrine system. In: Schmidt RF, Thews G (eds) Human Physiology. SpringerVerlag, Heidelberg, pp 658-687

37. Dallman MF, Akana SF, Scribner KA et al. (1992) Mortyn Jones memorial lecture. Stress, feedback and facilitation in the hypothalamo-pituitary adrenal axis. J Neuroendocrinol 4: 517-526

38. Kaiyala KJ, Woods SC, Schwartz MW (1995) New model for the regulation of energy balance and adiposity by the central nervous system. Am J Clin Nutr 62: 1123S-1134S

39. Yudkin JS (1993) Circulating proinsulin-like molecules. J Diabetic Complications 7: 113-123

40. Rhodes CJ, Alarcon C (1994) What beta-cell defect could lead to hyperproinsulinemia in NIDDM - some clues from recent advances made in understanding the proinsulin-processing mechanism. Diabetes 43: 511-517

41. Porte DJr (1991) Banting lecture 1990. Beta cells in type II diabetes. Diabetes 40: 166-180

42. Yoneda M, Tamasawa N, Takebe K et al. (1995) Central neuropeptide $Y$ enhances bile secretion through vagal and muscarinic but not nitric oxide pathways in rats. Peptides 16: $727-732$

43. Stubbs M, York DA (1991) Central glucocorticoid regulation of parasympathetic drive to pancreatic B-cells in the obese fa/fa rat. Int J Obesity 15: 547-553

44. Fletcher JM, McKenzie N (1988) The parasympathetic nervous system and glucocorticoid-mediated hyperinsulinae$\mathrm{mia}$ in the genetically obese (fa/fa) Zucker rat. J Endocrinol 118: 87-92

45. Siaud P, Puech R, Assenmacher I, Alonso G (1990) Adrenergic innervation of the dorsal vagal motor nucleus: possible involvement in inhibitory control of gastric acid and pancreatic insulin secretion. Cell Tissue Res 259: 535-542 